\title{
The Prospect of Cluster Analysis' Use to Obtain the New Scientific Results at the Example of Urotheliocytes' Study in Experimental Diabetic Cystopathy
}

\author{
Oksana Popadynets, Omelian Yurakh, Nadia Tokaruk, Galyna Yurakh, Ilona Pukach*, Mykhailo \\ Osypchuk ${ }^{1}$, Oleg Kolosov², Vita Korzhovska, Natalia Dubyna, Anatoliy Dmytrenko
}

\begin{abstract}
During the experiment on 70 adult male rats of the Wistar line the priority mechanisms of development of streptotrozotocin diabetic cystopathy were determined. It's morphometrically and statistically proved that the imbalance of the systemic mechanisms of the functioning of the transitional epithelium of the bladder starts from the first stages of the development of diabetic cystopathy and is not restored to the end of the experiment; it is associated with a violation of the structural and functional balance between the uroletocytes of clusters 4 and 1 and clusters 2 and 3 , as well as with a loss of urothelial bladder of morphological stratification.

The general pathological processes accompanying the diabetic cystopathy of a bladder development were revealed. According to the results of histological, morphometric, ultrastructural methods, biochemical studies of blood and urine, determination of water balance and cluster analysis, the main systemic and non-systemic factors that cause the development of these pathological processes were established.
\end{abstract}

\section{Keywords}

streptozotocin diabetes; diabetic cystopathy; urotheliocytes; transient epithelium; cluster analysis

Ivano-Frankivsk National Medical University, Ivano-Frankivsk, Ukraine

1 Vasyl Stefanyk Precarpathian National University, Ivano-Frankivsk, Ukraine

2 Department of Anesthesiology and Intensive Care of MCH (Municipal Clinical Hospital) \#1, Ivano-Frankivsk, Ukraine

*Corresponding author: ilonap624@gmail.com

\section{Problem statement and analysis of the recent research}

This article is a logical continuation of the scientific work, which was based on the results of cluster analysis of transitional epithelial cells (TE) of the bladder (UB) of rats in norm. In the previous article we stated that the use of cluster analysis in the context of experimental pathology opens wider opportunities for obtaining new results. For example, we chose an experimental diabetic cystopathy (DC), which was developed in laboratory rats on the background of simulated streptozotocin diabetes (SD).

Like the previous one, this article may serve as a methodological recommendation, first and foremost, for young scholars who want expand their scientific outlook. Such a methodical approach to obtaining new scientific results can be successfully applied to the study of cells of epithelial layers, which have a high ability for physiological and reparative regeneration (epithelial cells of the stomach, small and large intestines, air and urinary tract, vagina, endometrium, epidermis, etc.) both in norm and in different pathologies.
The most important things that were established in our previous studies are: 1) the most correct metric features for performing cluster analysis of cells of the TE of UB is the area of the profile field of its cells and their nuclei; 2) cluster analysis of urotheliocytes of UB should be performed in case of heterogenity of the cellular composition of its separate layers, which can be determined by the coefficient of variation; 3 ) the most important factor for urotheliocytes of UB is the coefficient of variation of their nuclear-cytoplasmic relations (NCR) which, besides the heterogeneity of the composition, also indicates the degree of their differentiation in each layer of the epithelial layer; 4) the most universal of agglomerationhierarchical methods which gives an opportunity to obtain new results on the number of clusters of the cellular composition of the epithelial layers, is the Vard method and the Euclidean metrics; 5) among iterative methods that determine the metric indices of cells of different clusters, it is enough to use the method k-means (Hartigan-Wong algorithm); 6) for figurative representation of the results of a cluster analysis, it is expedient to use cognitive graphics, the various elements of which are painted in different colors, each of which has 
its own definite content that makes it possible to draw certain conclusions without analyzing a large amount of data; the presentation of clustering results using the k-means method belongs to this graphics; 7) for the establishment of certain laws in morphological works morphological investigations are carried out at macro, micro and ultrastructural levels, which are supplemented by morphometric indices, descriptive and comparative statistics are used to confirm the evidence of obtained results; cluster analysis gives an additional opportunity to receive statistically substantiated new results, which objectively reflect existing relationships between objects and phenomena in numerical measurements; these new results require substantiation using both morphological, physiological, biochemical and other research methods.

For the first time due to these conditions we received in the norm four clusters (CL) of the urothelial cells of rats' UB, namely: CL 1, which according to our data is formed by basal urotheliocytes - cambial cells and, according to some authors $[2,5,12]$ differentiate into cells of other layers of TE; as we have established, CL 4 is formedby umbrella cells that form the urothelial barrier [5, 9, 12]; among intermediate urotheliocytes, which according to the literature are differentiating, are migrating cells $[2,5,9]$, we have identified two CL that metrically differ in size between cells and their nuclei and the level of NCR; and they differ morphologically in the number of urothelial vesicles and lysosomes, the severity of the Golgi complex (CL 2 is formed by moderately differentiated urotheliocytes and CL 3 - by highly differentiated ones).

During investigation of the cell composition of the TE of UB we have found that, particular attention should be paid to comparing the percentages of cells forming each of these clusters, namely: the absence of statistically significant differences between the particles of cells of CL 1 and of CL 4, that reflects the consistency between the proliferative potencies of basal urotheliocytes (CL 1) and the integrity of the urothelial cell barrier (CL 4), as well as between the percentages of CL 2 and of CL 3 cells, indicating a balance between the initial and final stages of differentiation of the intermediate cells of the urothelial UB.

Thus, the results of previous studies (using cluster analysis) indicate that there is a structural-functional equilibrium between the cells of the cluster pairs in norm, which reflects the morphometric features of functioning of the SM UB cells in normal conditions. That means, cluster analysis allows to approach the study of the cellular composition of the urothelia of the UB from the standpoint of structural analysis - a method of studying the sustained characteristics of the hierarchically ordered system (in our case, the system of cells of the TE UB) by indicating its subsystems and elements of different levels (the cells of different clusters in our case) and by determination of relations and connections between them.

\section{The objective of the study}

To show the possibilities of cluster analysis in obtaining new scientific results, to illustrate the examples of justification of new data on the basis of the results of histological, ultra- structure, biochemical methods of blood and urine research, study of water balance on the example of the study of UB cells on the background of the development of diabetic cystopathy, and also to provide an example of a comprehensive assessment of the pathomorphological reconstructing the urothelium using cognitive graphics.

\section{Materials and methods of research}

The study was performed on 70 male Wistar rats in the age of 12 months (10 animals were diabetic and 4 controls for each term of experiment). Diabetes mellitus was modeled by streptozotocin (60 mg / kg body weight). The material was collected at 14, 28, 42, 56 and 70 days of the experiment. TE of UB was studied on histological sections stained with hematoxylin and eosin ( $\mathrm{H} \& \mathrm{E})$, and was studied ultrastructurally according to the recommendations [21].

Morphometry was carried out by the program for analysis and processing of images Image J v. 1.47 (https : / / imagej.nih.gov/ij/), which is distributed with open source without license restrictions [7, 22]. The statistical analysis, including the cluster analysis, was performed in the software environment for statistical calculations and graphs R v. 3.0 (https: / / www.r-project.org/), which is also distributed without license restrictions [20]. Numerical data was presented as mean and standard deviation (Mean \pm SD). The cluster analysis was performed on the area of the profile fields (hereinafter - the area) of urothelial cells and their nuclei using the k-means method (Hartigan-Wong algorithm) $[1,4,8]$. Blood glucose levels were determined using the "Accu-Chek Active" glycemeter from the German firm "Roche Diagnostics GmbH". The level of glucose in urine and glucose in the blood during the collection of the material was established by glucose-oxidant method. $\mathrm{pH}$ measurements of urine were performed by the $\mathrm{pH}$ meter "Checker 1" ("Hanna Instruments"). The determination of the body mass of the rat was performed on a laboratory scale, and the mass of UB was measured on the electronic scale. Collection of urine was carried out in a metabolic chamber of our own design [26].

\section{Results of the research and their discussion}

The data, obtained in norm, was taken as the basis for the study of UB TE cells in DM, which causes the development of diabetic cystopathy. Since the number of clusters in the urothelial cellular cell was set to normal, only the iterative method of clustering k-means was used, which allowed to get the percentage of cells that form each cluster and the average area of the urothelial cells and their nuclei in each cluster, from which the NCR was calculated.

We first discovered that in the case of development of DM the structural and functional balance between the umbrella cells (CL 4) and basal urotheliocytes (CL 1), as well as between cells of CL 2 and of CL 3, is interrupted. 
The confirmation of this (Fig. 1) is statistically significant increased percentage of cells CL 1 in the range of 1.90-2.53 times and the decrease in the particles of cells CL 3 and 4 in 1.40-1.83 times and 1.42-2.30 times respectively from the 14 th day of experiment and in the following terms. At the same time, the proportion of CL 2 cells during the experiment did not change statistically significantly. Such a restructuring of cluster structures indicates an imbalance in the systemic mechanisms of the functioning of UB TE, which starts already from the earliest stages of the development of the SD and is not restored till the end of the experiment. These statistical results, which we received from the data of cell morphometry of TE and cluster analysis at each stage of the observation of DM development, are new (we did not find analogues in the available literature), but they need further justification.

So, already at the early stages of the development of the SD $[25,27]$ the desquamation of cells of CL 4 and of CL 3 develops in rats, which is manifested both in optical-optical (Fig. 2) and ultrastructural (Fig. 3) levels, and leads to a decrease in the percentages of cells of these clusters (see Fig. 1). We believe that extraction of UB TE cells at 14-28 days of the experiment results in high hydrostatic pressure of urine, the volume of which increases in these terms in 12, 14-18, 54 times [27]. The desquamation of the urothelial of UB with an experimental DM, which was presented only descriptively, was also indicated by other researchers $[9,11]$ only at later dates of the SD (at the end of the 8-9th week). Other authors $[4,31]$ revealed the desquamation of umbrella cells with various pathological effects much earlier: the first after - 72 hours, and the second - for 20 minutes after the action of the factor.

We found that on the 42nd and 56th days of SD development [27] the desquamation of the UB TE increases, which is identified both on the histological sections (Figure 4) and ultrastructurally (Fig. 5a, b). Urotheliocytes of all layers of TE undergo eradication, that leads to interruption of stratification (pathological change in the layered structure of PE) and the denudation of the basement membrane (Fig. 4b). The increase of desquamation of TE cells, as pointed out by some authors [6], contributes to the displacement of the reaction of urine to acidic. In our experiment starting from the 42nd day the $\mathrm{pH}$ of urine of diabetic rats was 6.08-5.53 [29]. Other authors are pointing on the loss of morphological stratification of TE during different cystopathies, namely, vibrational disease and chronic prostatitis [17]. It should be noted that along with the sites of TE in which there are pathological changes, there are areas where the urothelium slightly differs from the norm or control. A number of authors indicates such a polymorphism of changes in urotheliocytes during cystopathies $[9,16,18]$.

It is known that destruction of the urothelial cell barrier (urotheliocytes of CL 4) causes increased proliferative activity of cells of the basal layer of PE (urotheliocytes of CL 1), which are further differentiated into cells of other layers of the urothelium $[2,5,9,12,13,14]$. Obviously, in our experiment, a percentage increase of basal urotheliocytes (cells of CL1) is also a consequence of their proliferation.

Based on our data and literature data $[12,31]$ it can be considered that a decrease of the number of cells of CL 3 that we found, is indicator of a slowing down of the terminal (terminal) phase of differentiation of intermediate urotheliocytes of UB. At the same time, the initial stage of their differentiation does not suffer, as it is indicated by the absence of a statistically significant difference between the percentages of CL 2 cells of control and diabetic rats in all periods of SD development. By the way, R. E. Hurst et al. [10] notes that there is a defect in the terminal differentiation of the urothelial cells during some UB pathologies.

According to the morphometric and cluster analysis performed by us, it was found that on the 14-28 days of the experiment the average area of urotheliocytes in all clusters was increased by 1.21-1.40 times, and their nuclei - by 1.171, 44 times (Fig. 6). These results are original but need to determine the reasons of such changes.

We have investigated that the above-mentioned morphometric changes are due to the development of ballon dystrophy, which appears on histological preparations as light sections of the cytoplasm that do not permeate eosin (Fig. 7). Often these sites are localized around nuclei of urotheliocytes. Actually on histological sections it is evident that vacuolic dystrophy occurs simultaneously in urotheliocytes of all layers of TE, especially in the intermediate and basal, and may be less or more seen. At the ultrastructure level the vacuolal transformation of mitochondria is determined; inside of mitochondria there are of fine-grained, mesh or thin-fibric structures (Fig. 8a). Apoptotic nuclei can occur in these urotheliocytes (Fig. $8 b)$. At the same time, the expansion of the near-nuclear space, the expansion of the tubules and tanks of the endoplasmic net and the vacuolization of the mitochondria (Fig. 8c) are identified. Vacuoles are often arranged in the form of a ring around the nucleus (Fig. $8 \mathrm{~d}$ ). The latter explains the localization of the enlightened sections of the cytoplasm on histological preparations. Liquid is also accumulated in phagolysosomes where hydrolytic enzymes which break the molecular bonds of biopolymers with the addition of a water molecule, are activated. In such vacuoles it is possible to observe non-split residues of different magnitudes and densities (Fig. 8b, d). A number of authors indicate that after the damage of the urothelial barrier the transfer of urinary components, in particular water, into the deeper layers of the UB TE occurs [5, 14]. In our experiment this was especially favored by the desquamation of the urothelium, which sometimes could reach BM. It should be borne in mind that hyperglycemia causes osmotic diuresis, which leads to an increase in the 12-14-18.54 times daily volume of urine which has a low density on the 14-28 days of the experiment, as a result of a decrease in water reabsorption in proximal tubules and a nephronal loop. Two mechanisms may be involved in the transport of water from such urine to the urothelial cells: passive - diffusion according to the concentration gradient [12] and active - with the participation of aquatories (AQPs) [23] and urea conveyors 


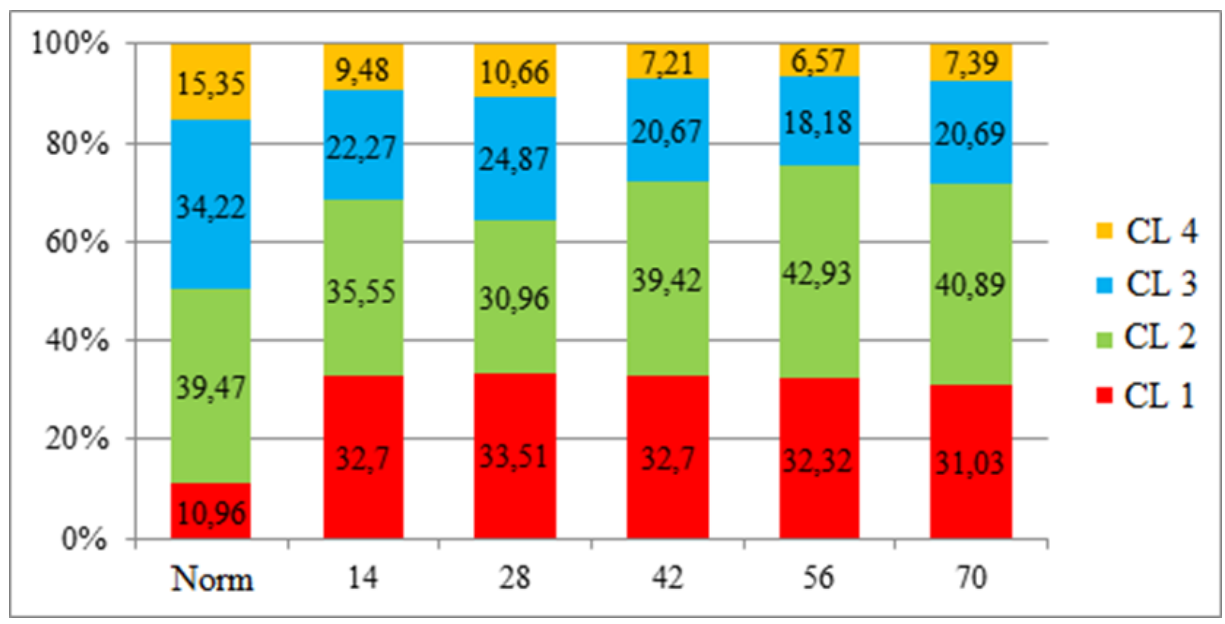

Figure 1. Particles of urotheliocytes of different clusters at the experimental stages. Below are the terms of observation (days).
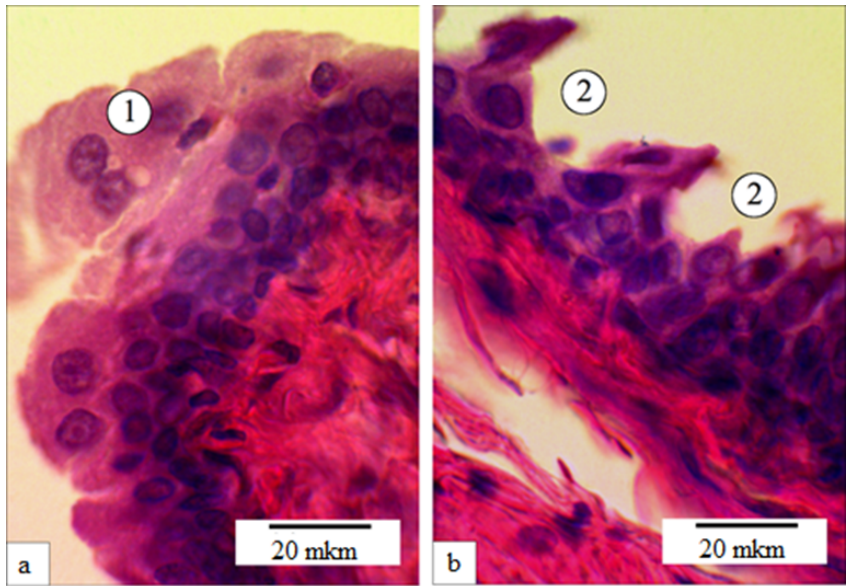

Figure 2. Desquamation of TE cells on the 14th (a) and 28th (b) day of the experiment. Staining: H \& E.

Magnification $\mathrm{x} 400.1$ - layer of cells that is excised; 2 "empty" areas remaining after desquamation.

(UTs) that modulate the size of urothelial cells and osmolarity of urine [23, 24].

Cells with vacuolic dystrophy occur less frequently in the following terms, and in the 70th day actually are undetectable. On 42-56th day cells in which the vacuoles were merged often appear into large blisters - cylinders that compress the nucleus and organelles (see Fig. 5, d). It is believed that such (balloon) dystrophy causes the development of focal colliculative necrosis of cells [3].

From the 42nd day till the end of the experiment (see Figure 6), there is a progressive decrease in the size of the cells of the TE and their nuclei, so that for the last term of the experiment the average areas of urotheliocytes of CL 1, 2, 3 and 4 become smaller by 1.07-1.24 times, and their nuclei - by 1.16-1.39 times. These results are obtained by morphometric and cluster analyzes and have a high degree of novelty, but they need to determine the reasons for such a transformation
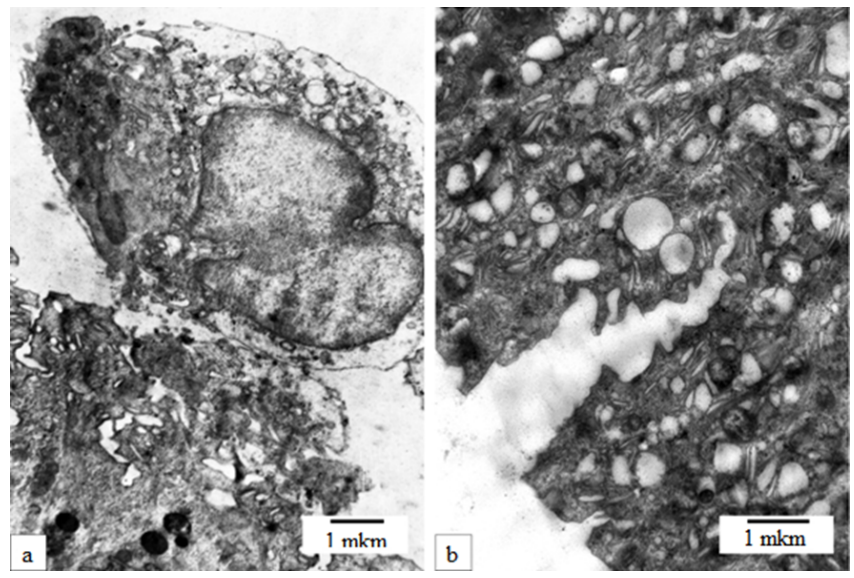

Figure 3. Desquamation of the umbrella cells of the TE and their wedge-shaped ruptures on the 14th (and) 28th (b) day of research. Electronic microphotos. Magnification x6400 (a) and $\mathrm{x} 8000(\mathrm{~b})$.

of TE cells like the previous ones.

It was found that on the 42-70th days of SD development the content of urotheliocytes that appears to be dehydrated increases (Fig. 9). Their matrix isosmiumophilic with low content of urothelial vesicles and reduced by cytoplasmic organelles. On the 56-70th days of the experiment, single urotheliocytes with clarified cytoplasm and secondary lysosomes that break up are determined along with such cells, indicating the predominance of lysis processes in the cytoplasm of these cells. Discontinuities of the binding complexes often occur in these terms leading to slit-like extensions between umbrella cells (Fig. 9b).

In our opinion, a decrease of size of TE cells and their nuclei and an increase in the content of dehydrated urotheliocytes is caused by glucosuria, which is the most common at these observation periods: the concentration of glucose in urine is $21.26-21.67 \mathrm{mmol} / \mathrm{l}$ and is higher than in control in 

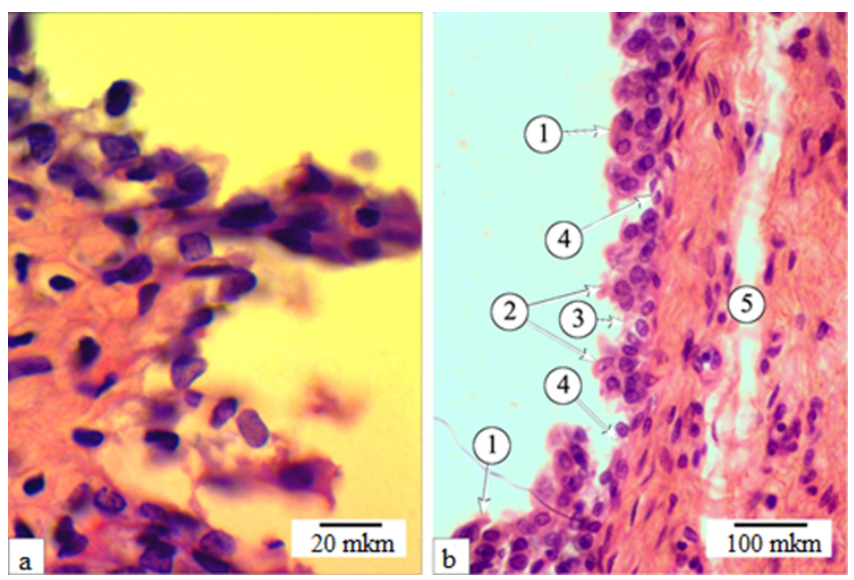

Figure 4. Total desquamation of TE on the 42nd (a) and violation of its stratification on the 56th (b) day of the experiment. Staining: H \& E. Magnification: $x 400$ (a) and x100 (b). Layers of TE cells remaining: 1 - three; 2 - two; 3 one; 4 - buckling BM; 5 - interstitial edema.

$22,61-22,81$ times. In this case, the diuresis of diabetic rats on this date decreases in 1.74-1.76 times comparing with the 28th day. Actually reducing diuresis with high glucosuria significantly increases the specific density of urine, whose osmotic pressure is higher than in urotheliocytes, and water derives out of cells thanks to gradient of concentration. As a result dehydration of urothelial cells develops. It is known from literature that TE cells lose water in hypertonic urine [2, 12]. That's why it should be added that during the period from the 28th to the 56th day of the experiment the desquamation of the urothelial cells of the UB still does not subsist, and there is a destruction of many connective complexes between the umbrella cells, which promotes the transfer of high specific density of urine from the intercellular spaces to the deeper layers of the TE. According to N. Montalbetti et al. such urothelial paracellular transport of substances is possible even without damage to the urothelial barrier. [15].

To our mind, the most accessible for the visual perception of clustering results using the $\mathrm{k}$-means method is presenting the results in the coordinate field in the form of cognitive graphics (Fig. 10). On fig. 10 the cluster structures of the cells of the UB TE are presented in norm and in different stages of development of the DM in a plane where the axis of abscissa is the area of urotheliocytes, and the ordinate axis is the area of their nuclei. Urotheliocytes of each cluster are marked by different colors: cells of CL 1, 2, 3 and 4, respectively - red, green, blue and orange. It is clear from the figure that on the 14th day of the development of the SD there is significant dilution of the elements of the cluster structure, especially of CL 4 and 3. There are numerous emissions (values which noticeably differ from the majority in the research group). Probably the reason for this is a powerful extraurothelial factor that significantly disturbs the system of cellular composition of TE. In our opinion, such factor is polyuria which occurs as
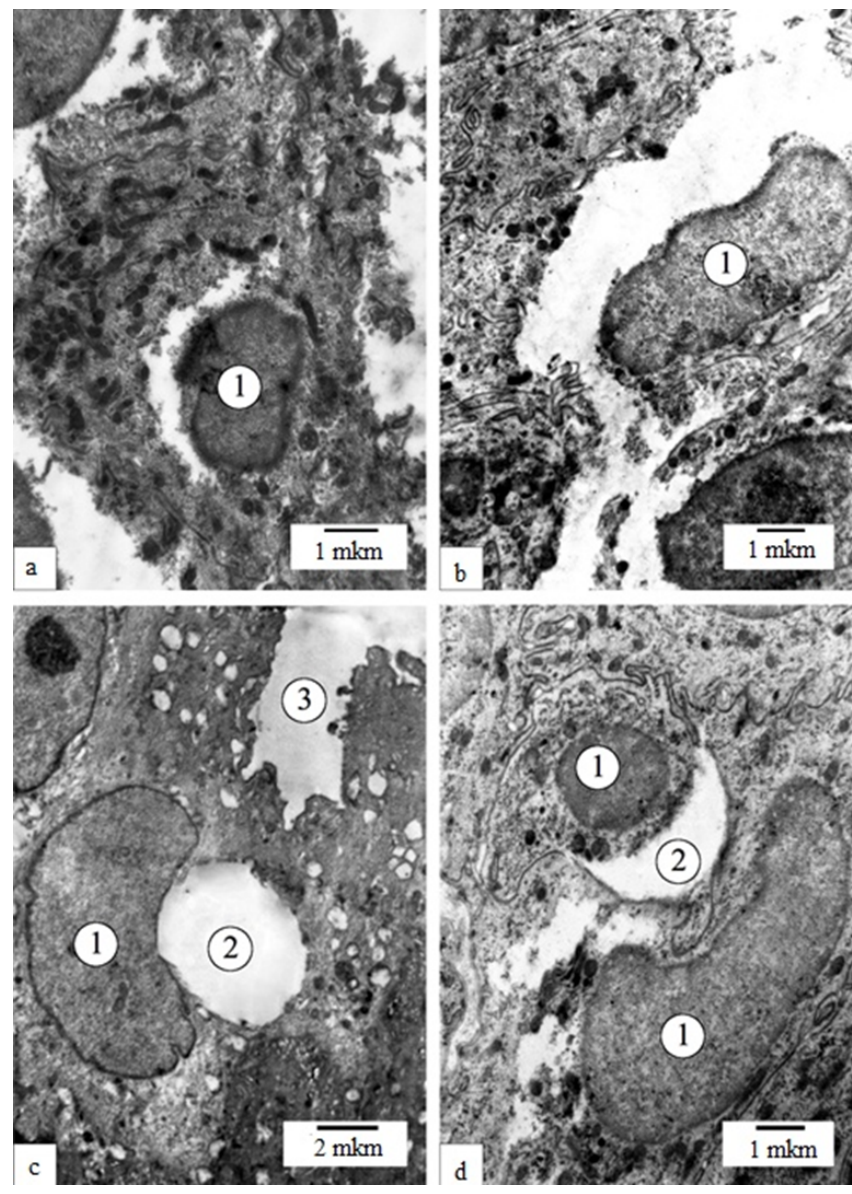

Figure 5. Total desquamation of the urothelial cells on the 42nd and 56th days of the experiment. Balloon dystrophy of umbilical (c) and basal (d) cells on the 56th day of diabetes development. Magnification: x6400 (a, b, g); x4000 (in). 1 nuclei of urotheliocytes; 2 - cylinders that compress the nucleus; 3 - section of destruction of the apex of the ambrella cells.

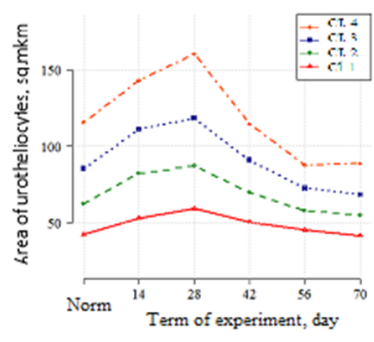

A

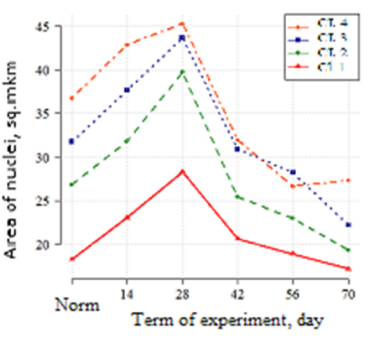

B
Figure 6. Change in the area of urotheliocytes (A) and their nuclei (B) in different clusters during streptozotocin diabetes.

a result of osmotic diuresis, which increases daily diuresis of diabetic rats in 12.14 times comparing with a norm [27]. As a 

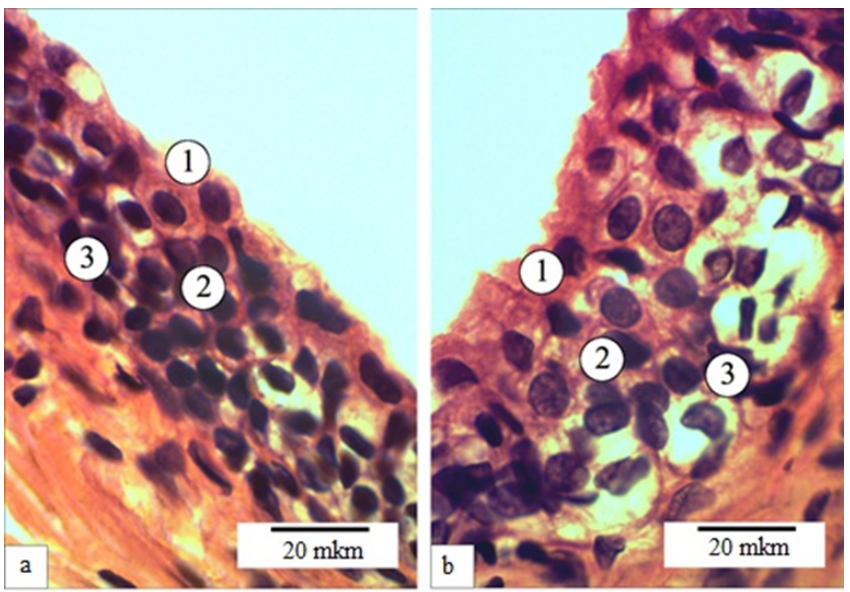

Figure 7. Ballon dystrophy of urothelial cells. Staining: H $\&$ E. Magnification: x400. Cells of surface (1), intermediate (2) and basal (3) layers of TE.

result, the hydrostatic pressure of a large volume of urine and the rapid filling of the UB destroy the urothelial barrier formed by the monoplate of umbrella cells. The latter stimulates the proliferation of basal urotheliocytes $[2,5,9,12,13,14]$ and triggers a cascade of pathomorphological changes.

On the 28th day of the experiment the rarity of the elements of the cluster structure and emissions increases, and the line on which the centers of the clusters are located bends (see Fig. 10). We believe that this is due to an increase of effect of extraurothelial factor (daily diuresis increases in 18.54 times). In addition, there is a new factor - aciduria [27].

A reverse process is observed since the 42 nd day of the SD - cluster elements are grouped around their centers (see Fig. 10); that indicates a decrease of the influence of the previous factor (diabetic rats daily diuresis decreases by 1.45 times comparing with the 28th day). On the 56th day of the experiment due to further reduction of diuresis (in 2.07 times) the area of the cluster structure of the urothelium becomes even smaller. It is important that the area of cluster structures in these two terms significantly decreases comparing with the norm. In addition, clusters are shifted to the center of the coordinates, indicating a decrease of the area of urothelial cells and their nuclei. Such a reorganization of the cluster structures of urotheliocytes on 42-56 days of the experiment shows that there were powerful impacts of the new non-systemic factor namely, significant glucosuria (the concentration of glucose in urinein these terms increases in 2.53-2.67 times comparing with the 28th day of the experiment).

Only on the 70th day of the development of SD (see Fig. 10) the area of the cluster structure of the cells of the UB TE does not change practically comparing with the previous term, and the line on which the centers of the CL stand approaches to the straight line and reminiscents the norm one. In general the cluster structure of the cellular structure of the urothelium in the last term of the experiment suggests that the cellular composition of the UB TE was adapted to the
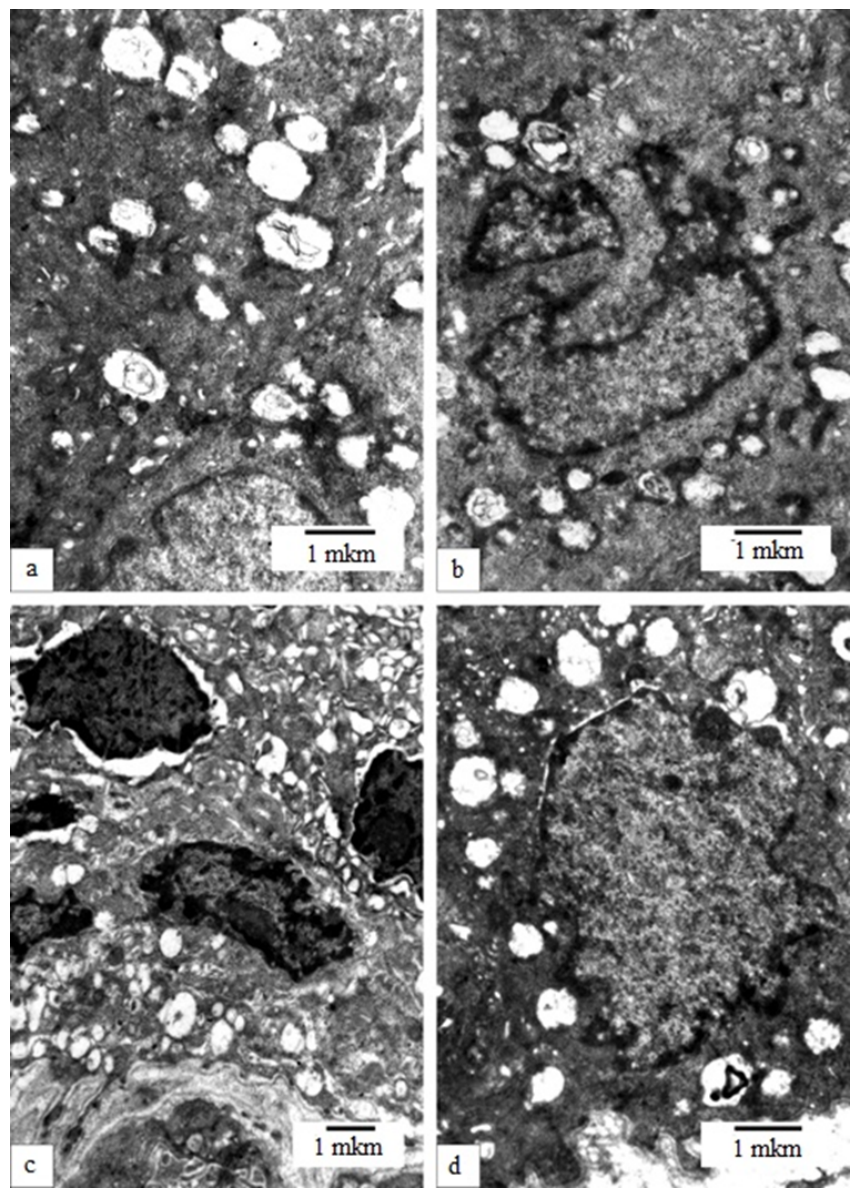

Figure 8. Ballon dystrophy of urotheliocytes of the superficial (a), intermediate (b) and basal (c, d) layers of TE of UB on the 14th (a, c) and 28th (b, d) days of the experiment. Swelling and vacuolal transformation of mitochondria (a,d), the presence of apoptotic nuclei (b), expansion of the tubules and tanks of the endoplasmic net, and the vacuolization of mitochondria with the extension of the near-nuclear space (c), the location of the vacuole in the form of a ring around the nucleus (g). Magnification: $x 8000$ (a, b, d); x6400 (c).

constant influence of extrasystem factors mentioned above.

Summarizing the above-said, it can be argued that the use of cluster analysis as a method of cognition, makes it possible to obtain new results, which require substantiation/confirmation in the future; this is possible with the use of not only morphological methods (histological, submicroscopic and morphometric) but also other methods of research (first of all biochemical, massometric, water balance studies and others - depending on the goal). Thus, a large array of numerical data obtained by different methods of research is created; it allows making a comprehensive assessment of the pathomorphological changes that have been made in morphology in the descriptive format. Moreover, the larger the data array - the greater the volume of descriptive information and the 

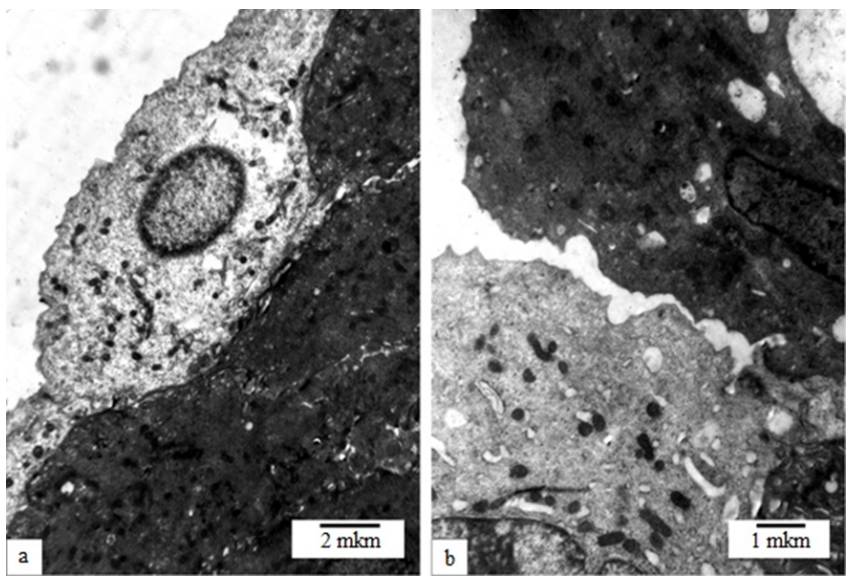

Figure 9. Single enlightened umbrella cells on the background of dehydrated osmophilic cells of the TE of UB on the 56th and 70th days of the experiment. Slit-like rupture of binding complexes between umbrella cells (b). Magnification: x4000 (a); x6400 (b).

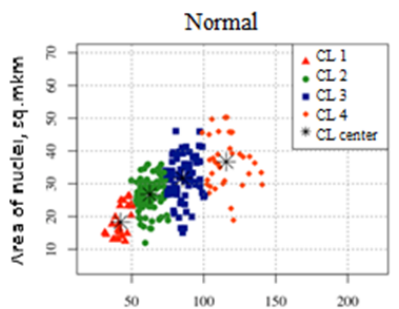

Area of urotheliocytes, sq.mkm

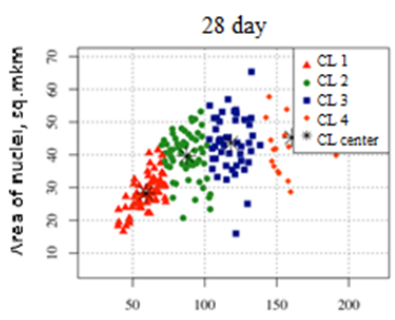

Area of urotheliocytes, sq. mkm

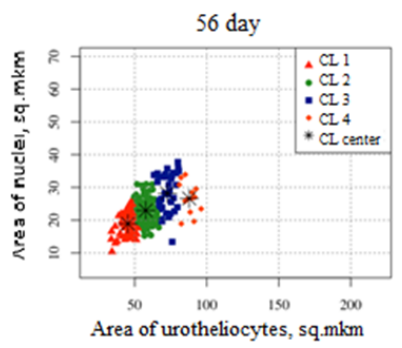

apply methods and techniques of cognitive graphics and to summarize the results in the form of schemes (Fig. 11).

Figure 11 combines both biochemical and morphological changes. In addition, with the help of arrows the connection between them is shown; it allows determining the priority directions of the development of pathomorphological processes without numerical analysis of a considerable volume of primary data. It should be noted that changes in the defining biochemical parameters (hyperglycemia, glucosuria) and diuresis are given in comparison with the control, which reduces the individual variability and helps to objectify the received data once again. Data on morphological and metric changes in the urotheliocytes' population is presented in the form of general abstract, which allows making a quick analysis of the cascade of pathomorphological changes. In this case, the isolation of the terms of observation contributes to the understanding of the phases of the restructuring of the urotherial composition of the UB TE depending on the duration of the influence of various factors.

Fig. 11 clearly shows that the entire cascade of changes is triggered by hyperglycemia, which is determined from the first observation period, increases until the 42nd day of the experiment and remains stable in the last two terms. Hyperglycemia is the cause of osmotic diuresis, which increases the daily volume of urine in 12.4-18.54 times in the first two terms comparing with control. In this case, the concentration of glucose in the urine increases only in 2.47-4.08 times. Due to a significant increase of diuresis and insignificant glucosuria the urine becomes of low density.

A large volume of urine on 14-28th days of the experiment causes growing desquamation and wedge-shaped gaps in umbrella cells and the restructuring of cluster structures of urothelium, and low-density urine enters the urothelial cells because of significantly increased diuresis; it leads to development of growing balloon dystrophy and increase of the size of cells of TE and their nuclei. Morphological manifestations of rheological disorders of blood which we have discovered are in the form of slugs in venules, interstitial edema, dystrophic changes in endothelial cells and minor violations of the structure of the basement membrane [28], and they do not significantly affect the pathomorphological changes of the urothelium cells in these terms.

During the 42-56th days of the experiment the effect of diuresis (Fig. 11) increases, which causes desquamation of the cells of the intermediate and basal layers of the urothelium, the discontinuities of the binding complexes, the expansion of the intercellular spaces, the merging of small vacuoles into the cylinders. In these terms high glucosuria and reduced diuresis significantly increase the specific urine density, which causes dehydration of urotheliocytes; it is ultrastructurally manifested by the consolidation of their cytoplasm and morphometrically confirmed by decreasing of the size of cells and their nuclei and increasing of the number of urotheliocytes with the cytoplasm of elevated electron density. These processes increase to the 70th day of the experiment that is more difficult it is to realize. In such cases, it is expedient to convert the text descriptions into logistic images, that is to
Figure 10. The cluster structures of transitional epithelium cells in the coordinate field in normal and at different times of development of streptotrozibic diabetes. 


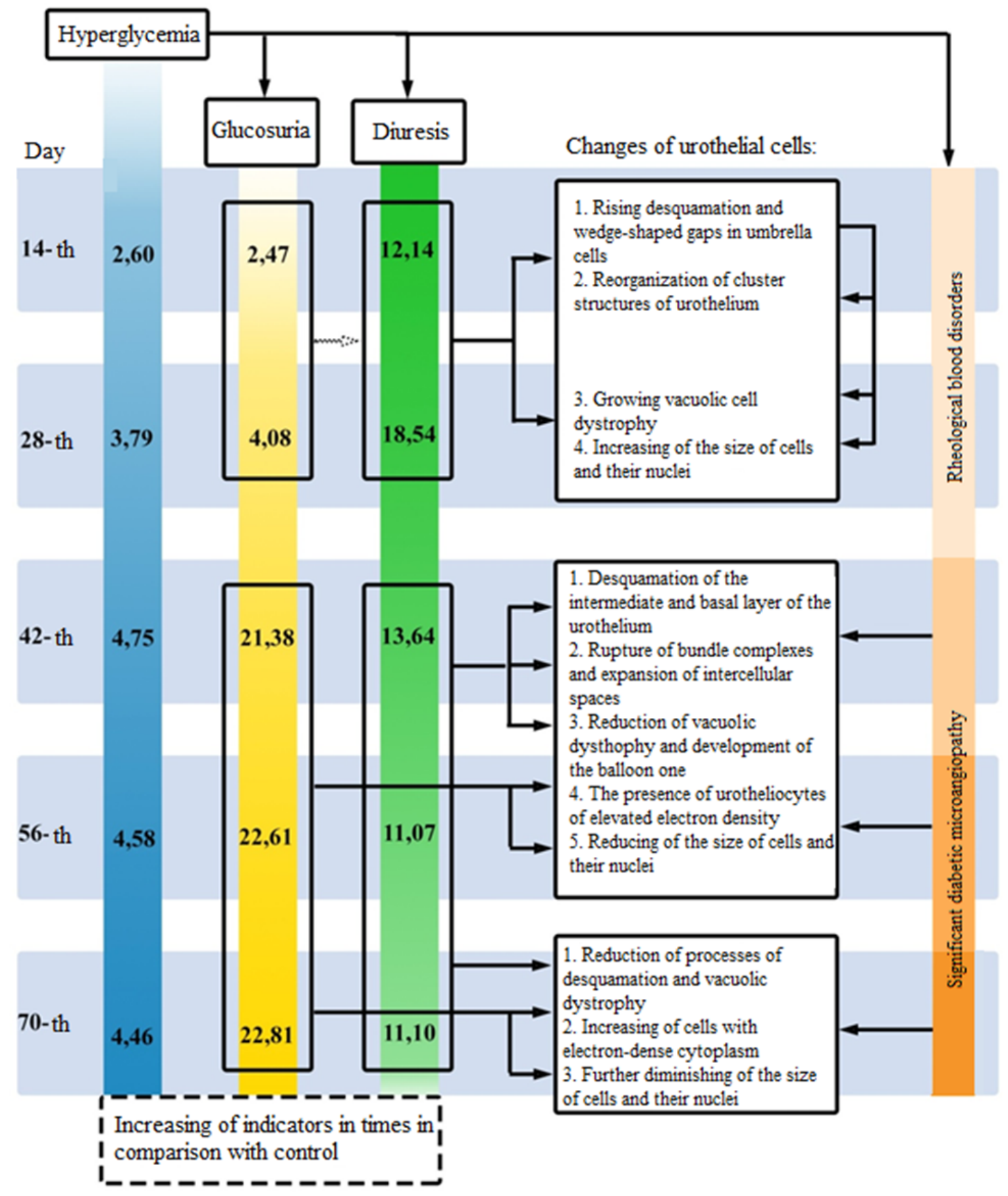

Figure 11. Morphofunctional changes of urothelial cells during the development of streptozotocine hyperglycemia. 
associated with an increase in the duration of effect of glucosuria on the ureter. Valid diabetic microangiopathy [28] also favors it; that is morphologically manifested by the generalization of the slag-syndrome with ponderable dystrophic and destructive changes of endothelial cells, significant violations of the structure of the capillary basement membrane and an increasing of the plasma penetration of perivascular connective tissue.

It should be noted that in the available literature you may find many examples of the use of cognitive graphics for figurative perception of the results of various observations. At the same time, it should be mentioned that the construction of cognitive graphics on the basis of cluster analysis of the studied parameters in any experimental or clinical pathology gives an opportunity to get a new vision of the development of various processes.

\section{Conclusions}

1. The application of cluster analysis, which can be used to classify objects for two or more metric features, in the study of any pathological processes gives prospects in obtaining new results that will reveal objectively existing links between objects and phenomena without difficult, labor-intensive and costly methods.

2. Objective characteristic of obtained cluster structures in the pathology can only be compared with cluster structures obtained in norm, which are determined in accordance with the purpose of well-thought-out and statistically substantiated research algorithms.

3. An assessment of the restructuring of cluster structures is a complicated task and it requires using other research methods apart from morphological and morphometric, as it was shown in the example of experimental diabetic cystopathy. The latter, in turn, leads to a significant increase in the mass of the obtained data, generalization of which allows to provide comprehensive assessment of pathological processes and to determine the priority directions in development of structural, biochemical and functional changes.

\section{Prospects for further research}

It is advisable to carry out cluster analysis of cells of epithelial layers, which have a high ability to physiological and reparative regeneration during other experimental pathologies.

\section{References}

[1] Abbas O. Comparisons between data clustering algorithms. Int. Arab J. Inf. Technol. 2008; 5(3): 320-325.

[2] Apodaca G. The uroepithelium: not jast a passive barrier. Traffic. 2004; 3:117-128. DOI: https : / / doi . org/10.1046/j.1600-0854.2003.00156.x [PMid:15086788]
[3] Avtsyn AP, Shakhlamov VA. Ultrastructural Foundations of Cell Pathology. Moskva: Medytsyna.1979; 320.

[4] Bakhshi M, Feizi-Derakhshi M, Zafarani E. Review and comparison between clustering algorithms with duplicate entities detection purpose. Int. J. Comp. Sci. Emerging Tech. 2012; 3: 108-114.

[5] Birder L, Andersson K-E. Urothelial signaling. Physiol. Rev. 2013; 93: 653-680. DOI: https://doi.org/ 10.1152 /physrev . 00030.2012 [PMid:23589830 PMCid:PMC3768101]

[6] Boykiv DP, Bodnarchuk TI, Ivankiv OL et al. Biochemical parameters in norm and in pathology: reference book. ed. Sklyarov OY. Kyiv: Meditsina. 2007. 320.

[7] Collins T. Image J for microscopy. BioTechniques. 2007; 43(1): 25-30. DOI: https://doi .org/10.2144/ 000112517 [PMid:17936939]

[8] Haldar P, Pavord ID, Shaw DE et al. Cluster analysis and clinical asthma. Am. J. Resp. Crit. Care Med. 2008; 178 (3): 218-224. DOI: https: / / doi.org/10.1164/rccm.200711-17540C [PMid:18480428 PMCid:PMC3992366]

[9] Hanna-Mitchell AT, Ruiz GW, Danechgari F et al. Impact of diabetes mellitus on bladder uroepithelial cells. Am. J. Physiol. Regul. Integr. Comp. Physiol. 2013; 304 (2): 8493. DOI: https: //doi.org/10.1152/a jpregu . 00129.2012 [PMid:23174855 PMCid:PMC3543662]

[10] Hurst RE, Moldwin RM,MulhollandSG. Bladder defense molecules, urothelial differentiation, urinary biomarkers, and interstitial cystitis. Urology.2007; 69: 17-23. DOI: https://doi.org/10.1016/j.urology . 2006.03 .083 [PMid:17462475]

[11] Ibrahim SH. Evaluation of time-dependent structural changes of rat urinary bladder in experimentally-induced diabetes mellitus light and electron microscopic study. Egypt. J. Urol. 2007; 30: 367-382.

[12] Khandelwal P, Abraham SN, Apodaca G. Cell biology and physiology of the uroepithelium. Am. J. Physiol. Renal. Physiol. 2009; 297 (6): 1477-1501. DOI: https : / / doi.org/10.1152/ajprenal .00327.2009 [PMid:19587142 PMCid:PMC2801337]

[13] Kreft ME,Romih R, Kreft M et al. Endocytotic activity of bladder superficial urothelial cells is inversely related to their differentiation stage. Differentiation. 2009; 77: 48-59. DOI: https://doi.org/10.1016/j. diff.2008.09.011 [PMid:19281764]

[14] Lavelle J, MeyersS, RamageR et al. Bladder permeability barrier: recovery from selective injury of surface epithelial cells.Am. J. Physiol. Renal. Physiol.2002; 
2: 242-253. DOI: https://doi.org/10.1152/ ajprenal.00307.2001 [PMid:12110507]

[15] Montalbetti N, Rued AC, Clayton DR et al. Increased urothelial paracellular transport promotes cystitis. Am. J. Physiol. Regul. Physiol. 2015; 309 (12): 1070-1081. DOI: https: //doi.org/10.1152/ajprenal.00200.2015 [PMid:26423859 PMCid:PMC4683306]

[16] Nepomniashchikh HY, Aydagulova SV, Nepomniashchikh DL. Stereotype variants of structural modification of urothelium with various pathological processes in the bladder and prostate gland. Biulleten eksperymentalnoy biologii i meditsiny. 2008; 146 (10): 395-399.

[17] Nepomniashchikh LM, Lushnikova YeL, Neymark AI. Remodeling of the muscular membrane (detrusor) of the hyperactive urinary bladder with prostatic hyperplasia. Biulleten eksperimentalnoy biologii i meditsiny. 2012; 153(5): 742-747.

[18] Nepomniashchikh LM, Aydagulova SV, Ivaninskiy OI et al. Biosynthetic reactions and ultrastructure of urothelial cells in chronic cystitis and cystopathies. Biulleten eksperimentalnoy biologii i meditsiny. 2002; 134(9): 349-355.

[19] Popadynets OH, Yurakh OM, Tokaruk NS et al. New approaches to obtaining scientific novelty in morphological studies of transitional epithelial bladder. Halytskyy likarskyy visnyk. 2017; 24(2): 37-47. DOI: https : //doi.org/10.21802/gmj.2017.2.11

[20] R Core Team R: a language and environment for statistical computing. Vienna, Austria: R Foundation for Statistical Computing. 2015.

[21] Sarkysov DS, Perova YL. Microscopic technology. Moskva: Meditsina. 1996; 544.

[22] Schneider CA, Rasband WS, Eliceiri KW. Nih image to imagej: 25 years of image analysis. Nature Methods. 2012; 9(7): 671-675. DOI: https://doi. org/10.1038/nmeth.2089 [PMid:22930834 PMCid:PMC5554542]

[23] Spector DA, Wade JB, Dillow $\mathrm{R}$ et al. Expression, localization, and regulation of aquaporin-1 to 3 in rat urothelial. Am. J. Physiol. Renal. Physiol. 2002; 282: 1034-1042. DOI: https://doi.org/10. 1152/ajprenal.00136.2001 [PMid:11997319]

[24] Spector DA, Yang Q, Wade JB. High urea and creatinine concentrations and urea transporter $\mathrm{b}$ in mammalian urinary tract tissues. Am. J. Physiol. Renal Physiol. 2007; 292 (1): 467-474. DOI: https://doi.org/10. 1152/a jprenal .00181.2006 [PMid:16849692]
[25] Tokaruk NS, Balashchuk O. Changes in morphometric parameters and cluster structure of the bladder urothelial cells on the 28th day of experimental diabetes. Information Booklet of XIII International Congress of Medical Sciences (Sofia, 8-11 May 2014). Sofia: 2014; 31.

[26] Tokaruk NS, Kotyk TL, Yurakh OM ta in. Patent \#97771 Ukraine. Metabolichna kamera dlya zaboru sechi dribnykh tvaryn.

[27] Tokaruk NS. Dynamics of morphofunctional changes of rat bladder under experimental diabetes mellitus. Galic'kij likars'kij visnik. 2015; 22(3): 2: 95-99.

[28] Tokaruk NS. Characterization of hematocrit of the urinary bladder of rats in diabetes mellitus. Aktualni problemy suchasnoyi medytsyny. 2016; 16(1): 249-255.

[29] Tokaruk NS. Characteristics of the transitional epithelium of the urinary bladder of rats in norm as a result of morphometric and cluster analysis. Svit medytsyny ta biolohii. 2015; 48(1): 163-166.

[30] Tokaruk NS. Morphological substantiation of the results of cluster analysis of transitional epithelium of the rat bladder in diabetes mellitus. Aktualni pytannya medychnoyi nauky ta praktyky. 2015; 82(2): 2: 480-488.

[31] Veranic P, Erman A, Kerec-Kos $\mathrm{M}$ et al. Rapid differentiation of superficial urothelial cells after chitosaninduced desquamation. Histochem Cell Biol. 2008; 131: 129-139. DOI: https://doi.org/10.1007/ s00418-008-0492-x [PMid:18797916]

[32] Yurakh OM, Popadynets OH, Zhurakivska OY et al. Experience of cluster analysis use in morphological research. Aktualni pytannya medychnoyi nauky [zb. nauk. prats]. DZ ”ZMAPO MOZ Ukrayiny”. 2015; 82(2): 2: 98-107.

Received: 27 Nov 2017

Revised: 28 Dec 2017

Accepted: 28 Dec 2017 